\title{
Análise da transformação da paisagem na vertente Oeste do Alto Curso do Arroio Guabiroba/ Sananduva-RS, de 1996 a 2015
}

\author{
Analysis of land use and land cover changes in the municipality of Sananduva, RS \\ with the help of remote sensing in the period 1996-2015
}

Ivete Rodrigues ${ }^{1}$, Janete Teresinha Reis ${ }^{2}$ e José Mário Leal Martins Costa ${ }^{2}$

\author{
${ }^{1}$ Universidade Federal de Santa Maria, RS, Brasil \\ iveterodrigues85@gmail.com \\ ${ }^{2}$ Universidade Federal da Fonteira Sul, RS, Brasil \\ janete.reis@uffs.edu.br; jose.costa@uffs.edu.br
}

\begin{abstract}
Resumo
Estudar a transformação da paisagem a partir da análise temporal e espacial significa compreender as relações físicas e sociais de um determinado espaço geográfico, pois, através desta análise é possível identificar os fatores que influenciaram e influenciam na sua modificação. A pesquisa busca analisar as transformações ocorridas na paisagem por meio do uso e cobertura do solo da vertente oeste no alto e médio curso do arroio Guabiroba no município de Sananduva- RS, entre os anos de 19962015. Sendo assim, buscou-se contextualizar histórico e espacialmente a transformação da paisagem a partir do povoamento do local, apontando os principais usos do solo ao longo do tempo histórico em escala local. A pesquisa baseou-se no método qualitativo por meio de entrevistas com os moradores e mapeamento do uso e cobertura do solo a fim de verificar a vegetação natural e exótica e as áreas agrícolas nos anos de 1996 e 2015. A partir da verificação e análise destas variáveis analisar as transformações na paisagem local. Como produto da análise constatou-se que a vegetação exótica tomou espaço de algumas áreas que em 1996 eram mata nativa e agricultura. No contexto geral na área de estudo a agricultura predomina incentivado pela modernização agrícola. Desse modo, a modernização agrícola acelerou o processo de transformação da paisagem e promoveu a redução da vegetação natural na área de estudo.
\end{abstract}

Palavras-chave: Uso do solo; Transformação; Paisagem; Area rural.

\begin{abstract}
Studying the landscape of transformation from the temporal and spatial analysis means understanding the physical and social relations of a given geographical area because, through this analysis it is possible to identify the factors that influenced and influence their modification. The research seeks to analyze the transformations in the landscape through the use and soil cover the western slope in the upper and middle course Guabiroba stream in the municipality of Sananduva- RS, between 1996 and 2015. Thus, we sought to contextualize historical and spatially the landscape of transformation from the local population, pointing out the main land uses along the historical time on a local scale. The research was based on qualitative method through interviews with residents and use mapping and land cover to check the natural and exotic vegetation and agricultural areas in 1996 and 2015. From the check and analysis of variables to analyze the changes in the local landscape. As a product of the analysis it was found that the exotic vegetation took space in some areas in 1996 were native forest and agriculture. In the general context in the study area agriculture predominates encouraged by agricultural modernization. Thus, agricultural modernization has accelerated the landscape transformation process and promoted the reduction of natural vegetation in the study area.
\end{abstract}

Keywords: Use of the soil; Transformation; Landscape; Rural area. 


\section{Introdução}

A evolução baseada na técnica da produção agrícola promoveu a transformação da paisagem dos diversos locais do mundo. Nas últimas décadas o crescimento e o fortalecimento da biotecnologia proporcionaram a ocorrência de mudanças, tanto nas áreas rurais, como urbanas.

Neste conjunto, tanto o espaço geográfico como o setor agropecuário tiveram que se adequar ao processo de transformação da paisagem, mais intensamente a partir da modernização agrícola. Assim, a utilização de insumos químicos, sementes selecionadas (transgênicas) e a mecanização das áreas agrícolas, foram à chave da modernização da agricultura que originaram a transformação da paisagem.

Desse modo, a modernização da agricultura, bem como a implementação de novas técnicas de produção proporcionaram mudanças na cobertura do solo. Aliado a isto, a biotecnologia e a modernização da base técnica de produção são fatores que contribuíram nas mudanças no uso do solo. Pois a evolução da técnica permitiu que os solos de um determinado local fossem usados intensivamente de forma diferenciada ao longo das décadas.

O uso intensivo do solo trouxe mudanças na cobertura vegetal e consequentemente ocasionou transformações e alterações significativas na paisagem das áreas rurais. Estas transformações se referem à retirada da vegetação e/ou na alteração da topografia, a fim de expandir a área agrícola.

Diante do exposto, observa-se que as áreas rurais do município de Sananduva- RS no decorrer dos anos, sofreram alterações significativas na sua paisagem. Com o advento da modernização, a vegetação sofreu retração significativa. Com este propósito, o presente estudo tem como objetivo analisar a transformação da paisagem a partir do uso do solo, onde a inserção da modernização na base técnica de produção agrícola ocorreu tardiamente. Mesmo assim, ocasionou alterações significativas da paisagem em curto espaço de tempo.

Para a realização desta pesquisa utilizou-se como área de estudo a vertente oeste da bacia hidrográfica do arroio Guabiroba em seu alto e médio curso, especificamente nas localidades rurais denominadas de Guabiroba Alta e Guabiroba Média, no município de Sananduva- RS.

Nesta pesquisa buscou-se analisar e discutir o uso do solo e a transformação na paisagem, considerando o recorte temporal de 1996 a 2015. Para a efetivação do trabalho, fez-se necessário um apanhado histórico do município e da área de estudo, a fim de compreender os possíveis usos do solo, desde o início do povoamento e a ocorrência da transformação na paisagem, que possivelmente foi acelerada com a colonização do local até os dias atuais.

Para analisar e discutir as transformações na paisagem a partir das mudanças no uso do solo na vertente oeste do arroio Guabiroba no município de Sananduva- RS foi necessário trazer o conceito de paisagem, uma vez que este é fundamental na análise das transformações ocorridas no espaço geográfico.

O conceito de paisagem foi abordado a partir da concepção de diversos autores e escolas da Geografia. A visão destes pesquisadores frente ao objeto de estudo, auxiliou na compreensão e no significado do termo, bem como sua aplicabilidade na ciência geográfica.

No decorrer da pesquisa foram explicitados os materiais e a metodologia utilizados. Para a análise da mudança no uso do solo, que implicou nas transformações na paisagem nos últimos 20 anos teve-se como base a elaboração de mapas, principalmente com relação as áreas agrícolas e as áreas de cobertura vegetal. O mapeamento de usos e cobertura do solo foi efetuado para os anos de 1996 e 2015.

\section{Objetivos}

\section{Objetivo Geral}

Analisar a variação na extensão da cobertura vegetal natural e de áreas agrícolas na vertente oeste do alto e médio curso da bacia hidrográfica do arroio Guabiroba no município de Sananduva- RS, entre os anos de 1996 e 2015, elencando o principal agente promotor da transformação da paisagem.

\section{Objetivos específicos}

- Analisar a transformação da paisagem natural a partir do povoamento do local e do uso do solo;

- Determinar os principais usos e as transformações da paisagem entre os anos de 1996-2015 em escala local;

- Elencar os principais fatores e agentes que contribuíram na aceleração da transformação da paisagem a partir do resgate histórico do povoamento e do uso do solo.

\section{Metodologia}

\section{Área de estudo}

A área de estudo localiza-se na zona rural do município de Sananduva- RS, compreendendo a vertente oeste da bacia hidrográfica do arroio Guabiroba em seu alto e médio curso. Encontra-se em altitude que varia aproximadamente entre 774 a 598 metros. Sua extensão é de aproximadamente nove quilômetros quadrados (Figura 1).

O município de Sananduva está situado na região nordeste do Rio Grande do Sul. Quanto à posição geográfica, suas coordenadas correspondem a $27^{\circ} 56^{\prime \prime} 52^{\prime \prime \prime}$ de latitude sul e $51^{\circ} 53^{\prime \prime} 46^{\prime \prime}$ de longitude oeste. Pertence a microrregião de Sananduva- RS, que abrange onze 


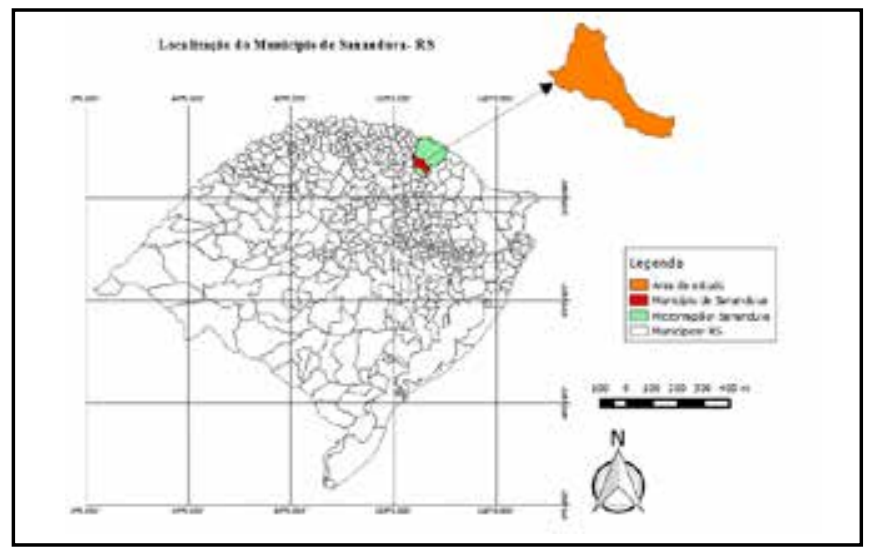

Figura 1 - Localização do município de Sananduva, onde está inserida a área de estudo

Municípios, são eles: Barracão; Cacique Doble; Ibiaça; Machadinho; Maximiliano de Almeida; Paim Filho; Sananduva; Santo Expedito do Sul; São João da Urtiga; São José do Ouro; Tupanci do Sul. Estes municípios possuem sua economia voltada, principalmente ao setor agropecuário.

\section{Dados cartográficos e orbitais}

No presente estudo, foram consideradas a cobertura vegetal remanescente e as áreas agrícolas entre os anos de 1996 e 2015, a fim de analisar a transformação da paisagem. Para a efetivação da pesquisa foram realizadas as seguintes etapas metodológicas:

i) revisão bibliográfica, através da busca de diversos referenciais teóricos sobre o município de SananduvaRS, e, sobre os seguintes conceitos: paisagem, espaço geográfico e modernização da agricultura.

ii) escolha e delimitação da área de estudo, a qual foi determinada a partir dos divisores de água da bacia. Com base nos limites territoriais do município, foram definidas as classes de uso e cobertura do solo.

iii) definição do período (1996 e 2015) e das classes de usos, como:

Floresta nativa: vegetação densa;

Área agrícola: áreas destinadas ao cultivo;

Floresta exótica: reflorestamento de eucalipto e pinus.

Para o mapeamento foram utilizadas imagens de satélite do ano de 1996 do satélite Landsat 5, sensor $\mathrm{TM}$, órbita 222, ponto 079 , com data de 28 de fevereiro de 1996. Para o mapeamento do uso e cobertura do solo do ano de 2015, utilizou-se da imagem satélite Landsat 8; sensor OLI; órbita 222; ponto 079, com data de 04 de março de 2015. Estas imagens foram adquiridas no Serviço Geológico dos Estados Unidos (USG).

Para a efetivação do processamento digital da imagem bem como a elaboração dos mapas da cobertura vegetal natural e o uso do solo utilizou-se o software SPRING 5.0.6.

A classificação foi supervisionada pixel a pixel com alocação de 30 amostras por polígono na imagem para cada classe temática. Após a classificação, as matrizes (imagens raster) foram convertidas para vetor, e posteriormente inseridas no módulo Scarta do Software Spring 5.0.6 para a elaboração da grade de coordenadas geográficas e do layout final.

Além da utilização de imagens de satélites para a elaboração dos mapas, também foram realizados trabalhos de campo, a fim de registrar imagens fotográficas e coleta de informações a partir de entrevistas semi- estruturada com os moradores do local.

Sendo assim, as informações obtidas através do trabalho de campo, registros fotográficos, imagens de satélite e entrevistas possibilitaram a realização da análise sobre a transformação da paisagem do local.

As entrevistas serviram como um complemento no estudo, para tanto estas foram realizadas com moradores que residem entre vinte anos ou mais no local, com idade correspondente entre 20 anos e 80 anos.

A área de estudo possui um total de aproximadamente 20 moradores, sendo que foram realizadas um total de 12 entrevistas com os agricultores. Estes agricultores pertencem à agricultura familiar e a área total de cada estabelecimento rural varia entre 12 a 45 hectares aproximadamente.

\section{Resultados}

Os mapas a seguir mostram a cobertura e uso do solo nos anos de 1996 e 2015. Por meio da comparação e análise destes mapas é possível verificar as mudanças na cobertura do solo, onde a vegetação sofreu retração ao longo das décadas, enquanto que a agricultura se expande.

Considerando os mapas apresentados anteriormente verifica-se que a paisagem na área de estudo se caracteriza pela predominância das áreas agrícola. A partir da intensificação do povoamento do local, ocorreu processo de aceleração na transformação da paisagem, deste modo, a agricultura passou a ser o elemento constituinte na paisagem ganhando cada vez mais destaque rural.

\section{Uso do solo}

\section{Uso do solo no ano de 1996}

No mapeamento do uso do solo foram consideradas a cobertura vegetal remanescente e as áreas agrícolas entre os anos de 1996 e 2015, a fim de analisar o uso do solo e a transformação da paisagem (Tabela 1).

A análise dos resultados apresentados na tabela $1 \mathrm{e}$ no mapa do uso do solo (figura 2) demonstram que as áreas agrícolas em 1996, já ocupavam uma área de 6,376 $\mathrm{Km}^{2},(68,72 \%)$ da área de estudo, as áreas de florestas ocupavam uma área de $2,902 \mathrm{Km}^{2},(31,28 \%)$ totalizando os $100 \%$ da área. 
Tabela 1 - Quantificação das classes do uso do solo em 1996

\begin{tabular}{c|c|c}
\hline Classes & Área $\left(\mathbf{K m}^{2}\right)$ & $\mathbf{\%}$ \\
\hline Floresta nativa & 2,902 & 31,28 \\
\hline Área agrícola & 6,376 & 68,72 \\
\hline Totais & 9,278 & 100 \\
\hline
\end{tabular}

\section{Uso do solo no ano de 2015}

Os dados oriundos do mapeamento do uso e cobertura do solo de 2015 da vertente oeste do arroio Guabiroba em seu alto e médio curso (figura 3 e tabela 2). As áreas de florestas tiveram relevante diminuição neste período, passando de 2,902 $\mathrm{km}^{2}(31,28 \%)$ para $2,471 \mathrm{Km}^{2}(26,64 \%)$.

Este fato foi causado pela expansão das áreas agrícolas. Pois, estas tiveram um significativo aumento, neste período, passando de uma área de $6.376 \mathrm{Km}^{2}$ para uma área de $6.590 \mathrm{Km}^{2}$, de uma área total de $9,0 \mathrm{~km}^{2}$

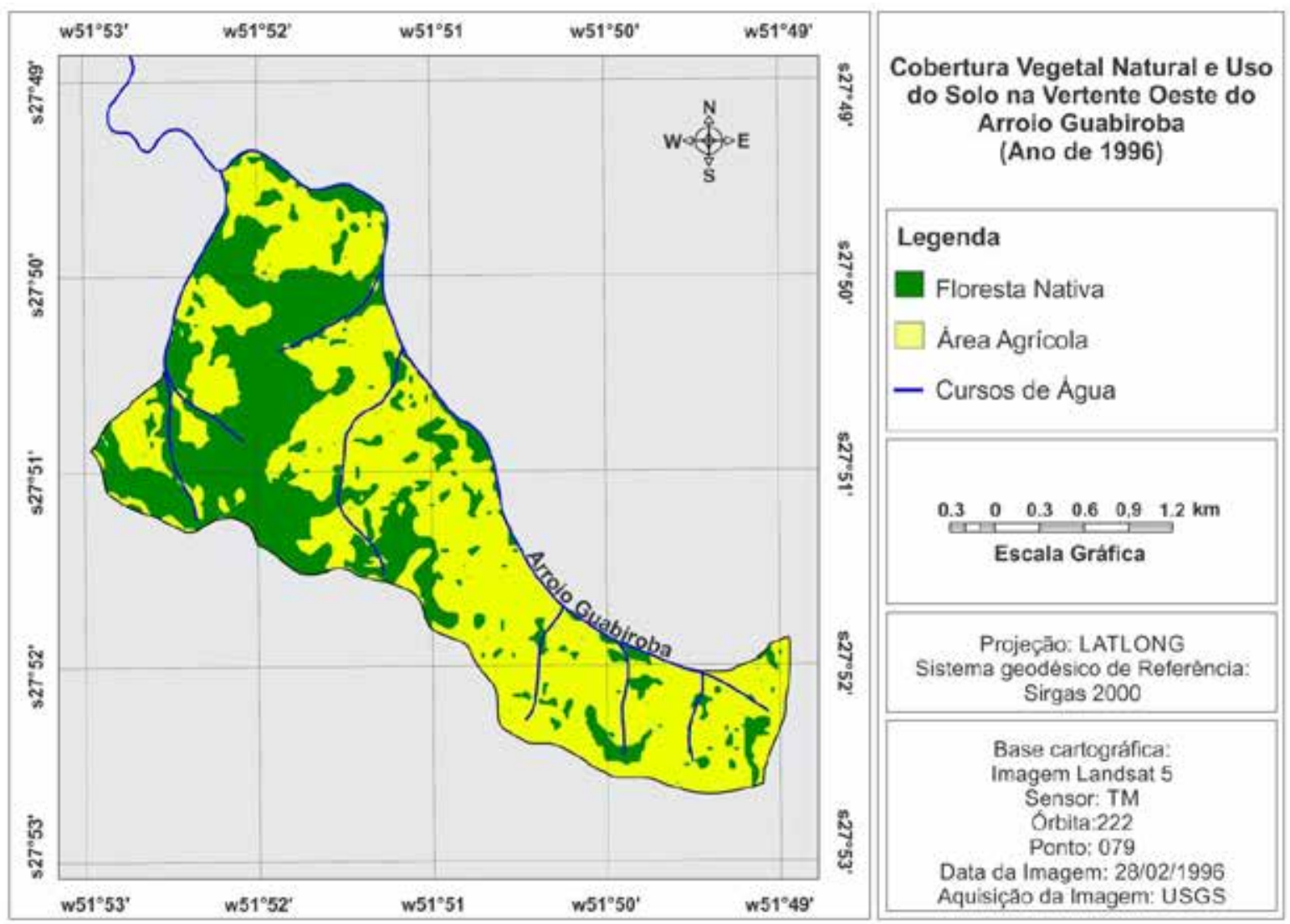

Figura 2 - Mapa do da Cobertura vegetal natural e uso do solo no ano de 1996 Fonte: Rodrigues, 2015

Considerando a distribuição dos diferentes tipos de uso e cobertura do solo, verifica-se que as concentrações das áreas agrícolas estão no alto e baixo curso dos rios e nas áreas de várzea. Assim, evidencia-se que o cultivo agrícola se desenvolve nas áreas com topografia mais plana, característica que favorece a mecanização da produção e maior produtividade.

Já as florestas concentram-se nas encostas dos morros com declive acentuado. Pode-se destacar que devido a topografia mais íngreme enfrenta-se maiores dificuldades para o cultivo agrícola.
Tabela 2 - Quantificação das classes do uso do solo em 2015

\begin{tabular}{c|c|c}
\hline Classes & Área $\left(\mathbf{K m}^{\mathbf{2}}\right)$ & $\mathbf{\%}$ \\
\hline Floresta nativa & 2,471 & 26,64 \\
\hline Área agrícola & 6,59 & 71,03 \\
\hline Floresta exótica & 0,216 & 2,33 \\
\hline Totais & 9,277 & 100 \\
\hline
\end{tabular}

A análise do uso do solo de 1996 (figura 2) destaca, que as áreas agrícolas que predominavam nas áreas mais planas e várzeas (1996), décadas após (2015), estavam em 


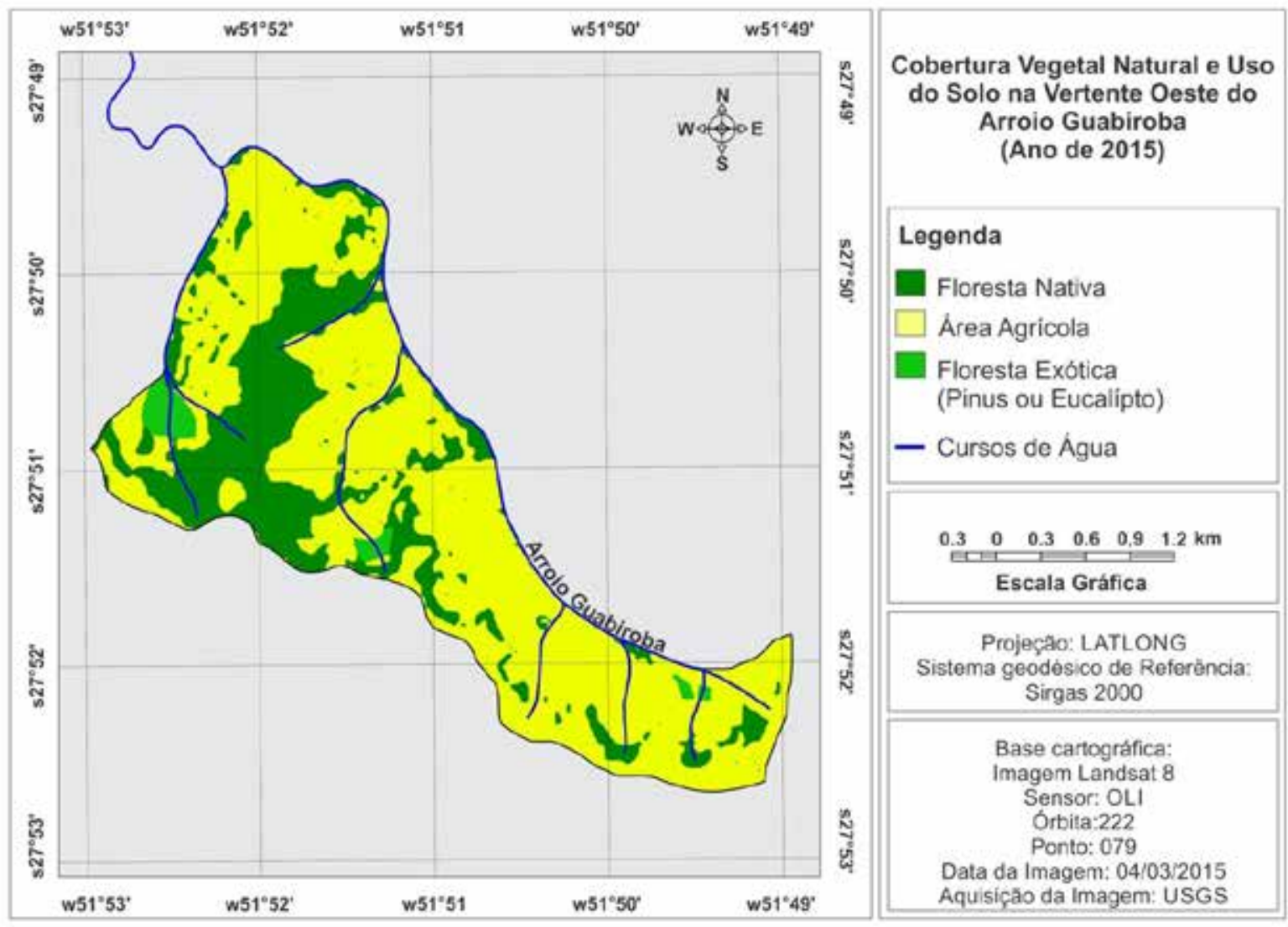

Figura 3 - Mapa da cobertura vegetal natural e uso do solo para o ano de 2015 Fonte: Rodrigues, 2015

um processo de expansão para as áreas mais íngremes, no alto e médio curso do rio. Evidenciando-se assim, uma intensa alteração na paisagem, no qual, a cobertura vegetal é retirada e as atividades agrícolas se expandem.

O uso e cobertura do solo mapeados, a partir da imagem de satélite Landsat 8 , sensor OLI, orbita e ponto $222 / 079$, tomados em 04/03/2015, podem ser visualizados na figura 3. Já a tabela 4 apresenta as áreas em $\mathrm{Km}^{2} \mathrm{e}$ os percentuais das três classes do mapeamento.

\subsubsection{Uso do solo em 1996 e 2015}

Analisando os resultados referentes às classes de uso do solo dos anos pesquisados (1996 e 2015 período analisado, destaca-se que as áreas de floresta tiveram significativa retração, dando espaço para as áreas agrícolas). Pois, representa uma significativa mudança no uso do solo da vertente oeste do arroio Guabiroba.

Pode-se destacar que as áreas de florestas permaneceram principalmente em áreas extremamente íngremes, no qual ainda maquinários agrícolas não podem chegar. A agricultura foi à única classe que teve uma expressiva expansão.

A integração dos mapas dos anos estudados permitiu espacializar à expansão das áreas agrícolas. A figura 4 mostra de forma qualitativa, que não se teve expansão das áreas agrícolas na área de estudo entre os anos de 1996 e 2015. Porém, analisando a floresta nativa constata-se uma diminuição e a floresta exótica passou a ser cultivada na área de estudo (Figura 4).

A partir da figura 5 pode-se observar de forma quantitativa a variação positiva dos produtos agrícolas cultivados nos períodos de 1996, 2000, 2004, 2008 e 2012.

Constata-se que no ano de 1996 o plantio de milho assumiu destaque seguida da soja e trigo, produtos demandados para o mercado no momento. Entretanto, a partir do ano 2000, os principais produtos agrícolas cultivos passaram a ser: soja em primeira instância, seguida do milho e trigo.

Atualmente, o principal produto cultivado continua sendo a soja e o milho. Pois, a área de soja plantada é de aproximadamente 20.000 hectares.

A produção agrícola ocorre de forma variada atendendo as exigências do mercado. Desse modo, a produção agrícola do município está inserida na produção destinada para a exportação produzindo principalmente produtos com este viés, cujos produtos causaram alterações significativas na paisagem local, dando preferência as culturas temporárias.

Com base no levantamento de informações e no trabalho de campo, nota-se que o uso do solo passou por uma (re) organização espacial a partir da inserção 


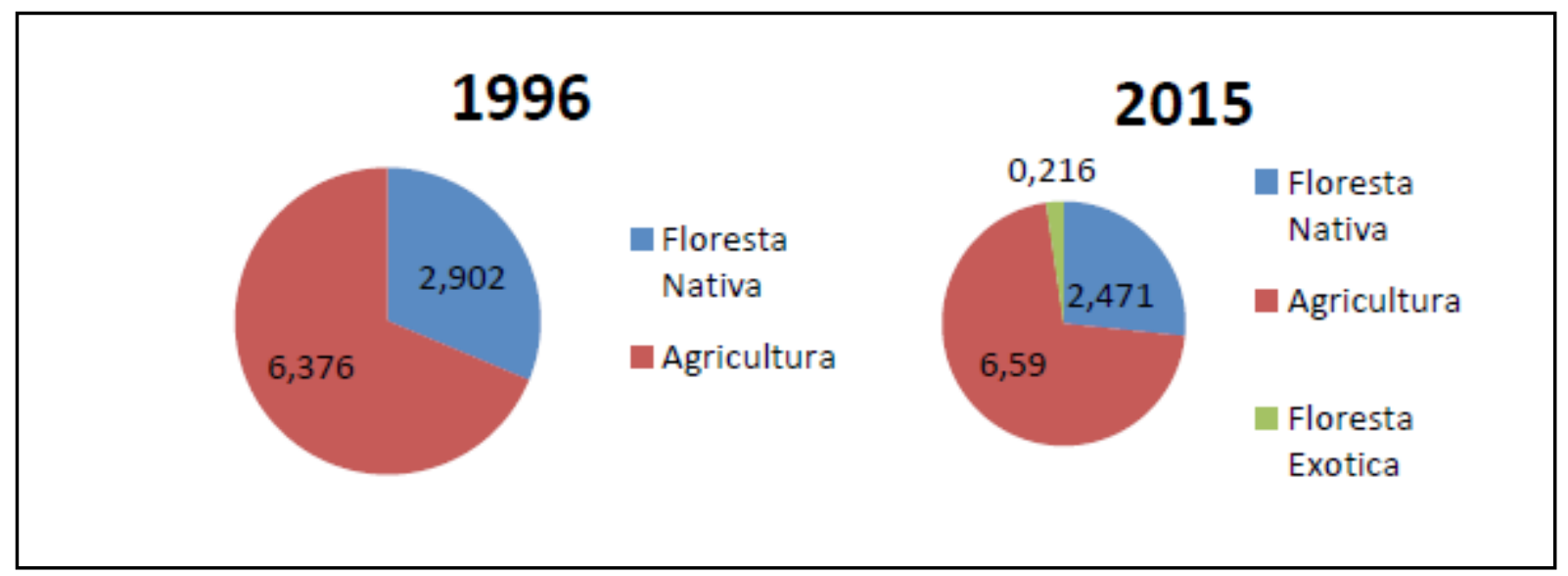

Figura 4 - Expansão das áreas de agricultura a vertente oeste do arroio Guabiroba, Sananduva-RS Fonte: Imagens Landsat5 e Landsat8, 2015

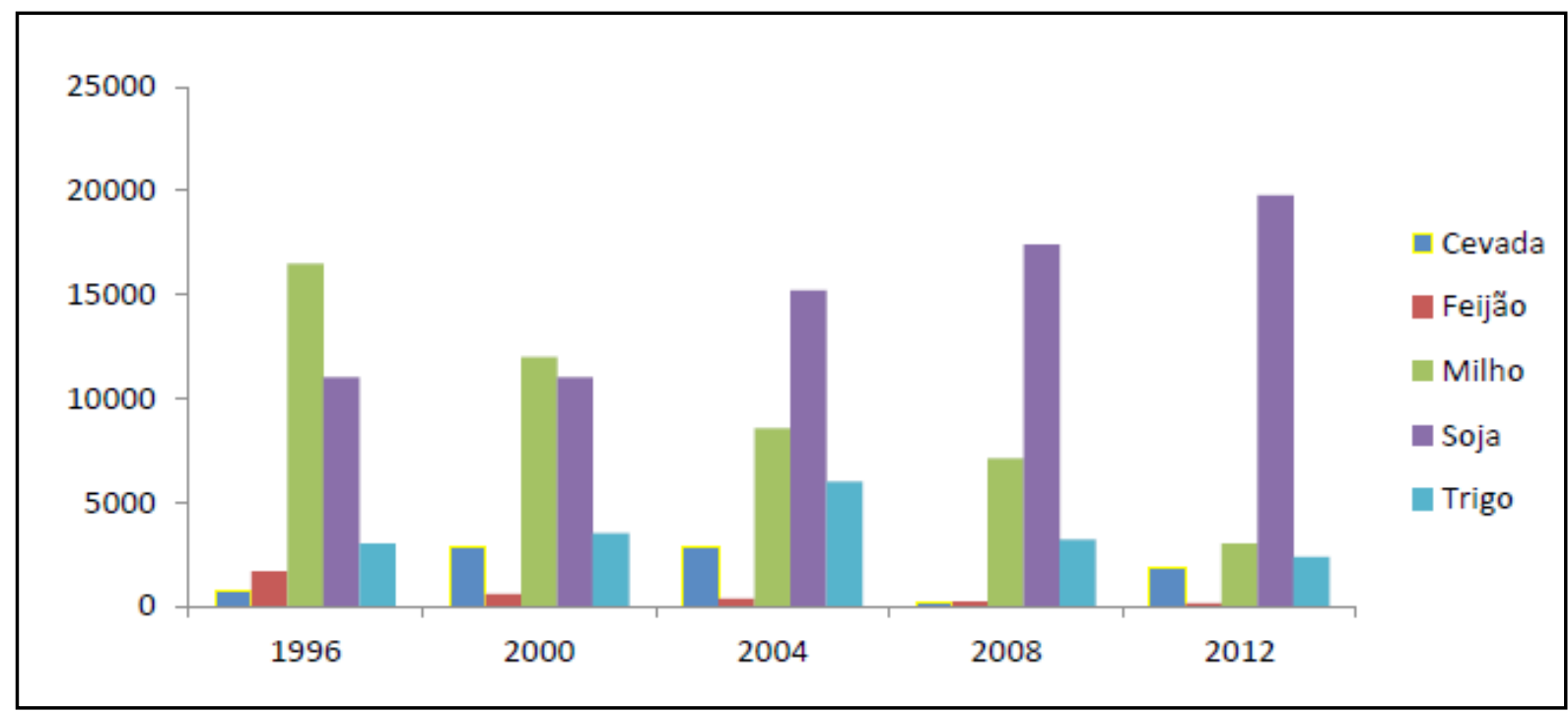

Figura 5 - Variação da produção agrícola entre os anos de 1996- 2012

Fonte: http://www.sidra.ibge.gov.br/. Acessado em 20/04/2015

da modernização agrícola. Este fator foi fundamental para a ocorrência da transformação da paisagem, das relações do trabalho e a expansão da área agrícola local.

A produção agrícola na área de estudo passou a ser cultivado com uso de produtos agroquímicos a partir de meados de 1970. Aliado a isto, as lavouras passaram a ser mecanizadas, mais intensamente a partir do ano de 2000 incorporando-se ao agronegócio. Atualmente a maioria dos estabelecimentos agropecuários possuem suas lavouras mecanizadas (Figura 6).

Com a introdução da mecanização as áreas agrícolas se expandiram ocasionando mudanças significativas, tanto espacialmente como temporariamente, repercutindo negativamente sobre o ambiente. Em decorrência da mecanização e introdução de produtos agroquímicos ocorreu a diminuição da fauna e flora, provocando em alguns casos a extinção de algumas espécies da fauna local.

\section{A transformação na paisagem}

A paisagem pode ser caracterizada pela sua dinâmica geomorfológica, pedológica, vegetal e de ocupação e uso, entre outros elementos socioculturais e econômicos que a diversifica.

A partir do estudo histórico-geográfico e análise das categorias espaciais apresentadas nos mapas foi possível identificar os elementos que contribuíram no uso e ocupação do solo acelerando o processo de transformação da paisagem.

Um dos fatores que condicionou a transformação da paisagem foi a derrubada da floresta e a introdução do setor agropecuários. A modernização agrícola, ou seja, a modernização da base técnica de produção foi o fator que mais acelerou o processo de transformação da paisagem.

$\mathrm{Na}$ vertente oeste da bacia hidrográfica do arroio Guabiroba destaca-se a presença do potencial natural, 


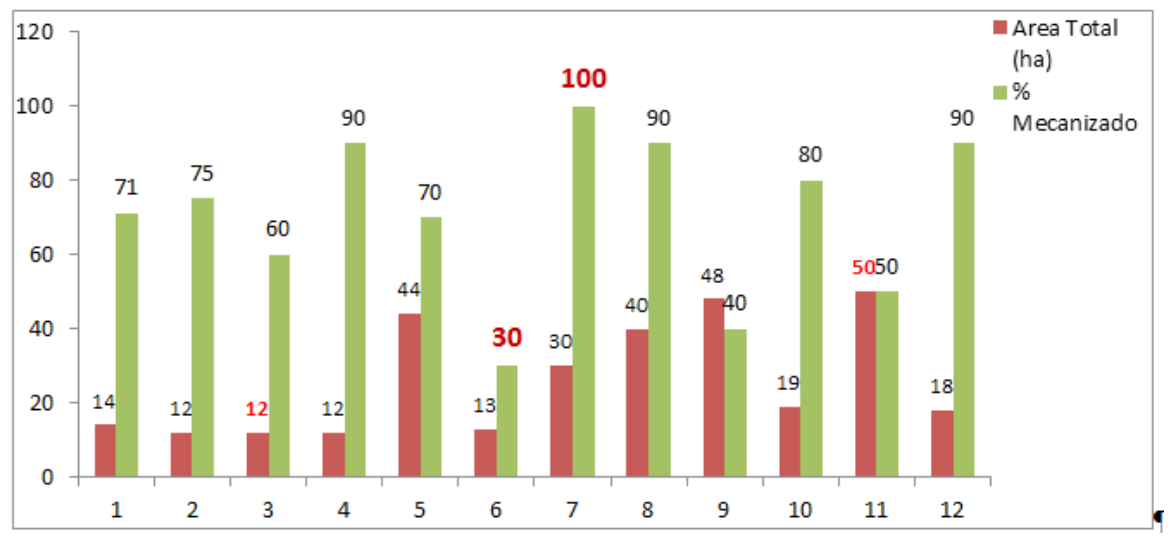

Figura 6

Fonte: Censo Agropecuário (1995 e 2006)- IBGE

tais como: relevo, clima, solo condicionaram a apropriação humana.

No entanto, é por meio do uso do solo e da prática da agropecuária que as paisagens se (re) configuram temporalmente, ora apresentam cobertura de produtos agrícolas diversificados, outros períodos com pastagens e presença do rebanho bovino. No entanto, a mecanização marcou o início da modificação da paisagem, do relevo e a expansão das áreas de lavouras agrícolas.

Como observado no mapeamento, bem como nas imagens apresentadas é comum encontrar áreas com a topografia do relevo aplainada (Figura 7). Estes rebaixamentos ocorreram devido à construção de patamares os quais facilitam a entrada da mecanização agrícola.

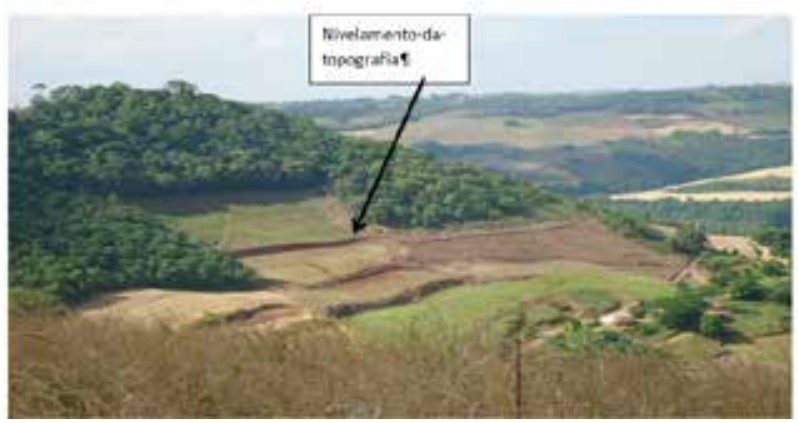

Figura 7 - Construção de nivelamento da topografia do relevo

Estas áreas são adequadas à entrada de máquinas que contribuem na aceleração da produção. Por isso, é importante destacar que a transformação da paisagem na vertente oeste do Arroio Guabiroba não se caracteriza somente pela retirada da vegetação natural, mas também pelo rebaixamento do relevo, pela entrada da vegetação exótica nos estabelecimentos agropecuários. Para Dantas "a modernização da agricultura alterou outros setores da sociedade, tendo impactos não só econômicos, mas sociais, culturais e ambientais" (DANTAS, 2011, p.15).

A transformação da paisagem natural faz com que ocorram algumas alterações também no biótico, na de- gradação do solo, no regime fluvial, entre outros. Estas alterações impactam na perda da biodiversidade além de trazer outras características paisagísticas locais.

A introdução de culturas como a soja e o milho agridem os atributos culturais e físicos desta paisagem. As introduções destas monoculturas conduzem a uma descaracterização específica da paisagem. Pois, a modernização da base técnica aliada à intensificação do uso de agroquímicos, alteraram as formas de produção agrícola no campo. Decorrente desta modernização ocorreu à expansão da área agrícola trazendo transformações, como a retração da vegetação e o rebaixamento do relevo que são perceptíveis na paisagem.

Este novo modelo no sistema produtivo trouxe consigo fatores que condicionaram as mudanças nas ações, na forma de pensar, de agir e com isso perdem-se usos e costumes que foram importantes no cotidiano dos agricultores e na constituição do espaço de vivência local. Além de promover a migração de agricultores do campo para a cidade, os dados demonstram a diminuição na quantidade de pessoas residentes no campo (Figura 8).

As transformações socioambientais que ocorrem na paisagem do meio rural resultaram da ação humana condicionada ao sistema econômico vigente. Dentro desta perspectiva Santa (2002, p.29) afirma que o espaço pode ser compreendido como produto da relação homem com a natureza, na qual a natureza é transformada por meio da técnica.

A modernização na base técnica de produção bem como as políticas públicas tais como o PRONAF (Programa Nacional da Agricultura Familiar) contribuíram na expansão da área agrícola plantada. Sendo assim, a paisagem passou a ser transformada.

Atualmente, os estabelecimentos rurais possuem sua fonte de renda baseada principalmente na agricultura e pecuária (Figura 9), sendo que a produção agrícola do local é destinada à exportação.

Um dos fatores que levou a esta mudança populacional foi a modernização agrícola, a qual promoveu conflitualidades e exclusão daqueles agricultores que 


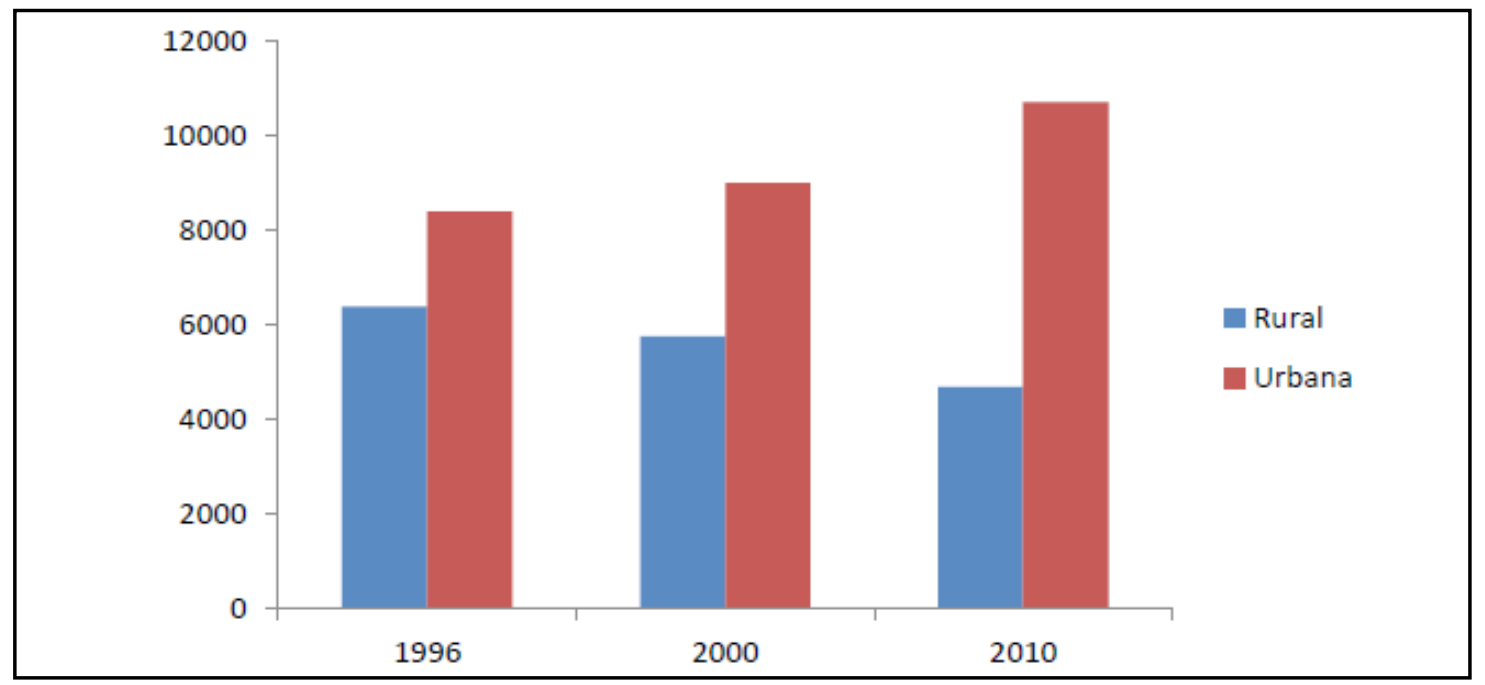

Figura 8 - População rural e urbana do município de Sananduva- RS. Fonte: IBGE, 2010

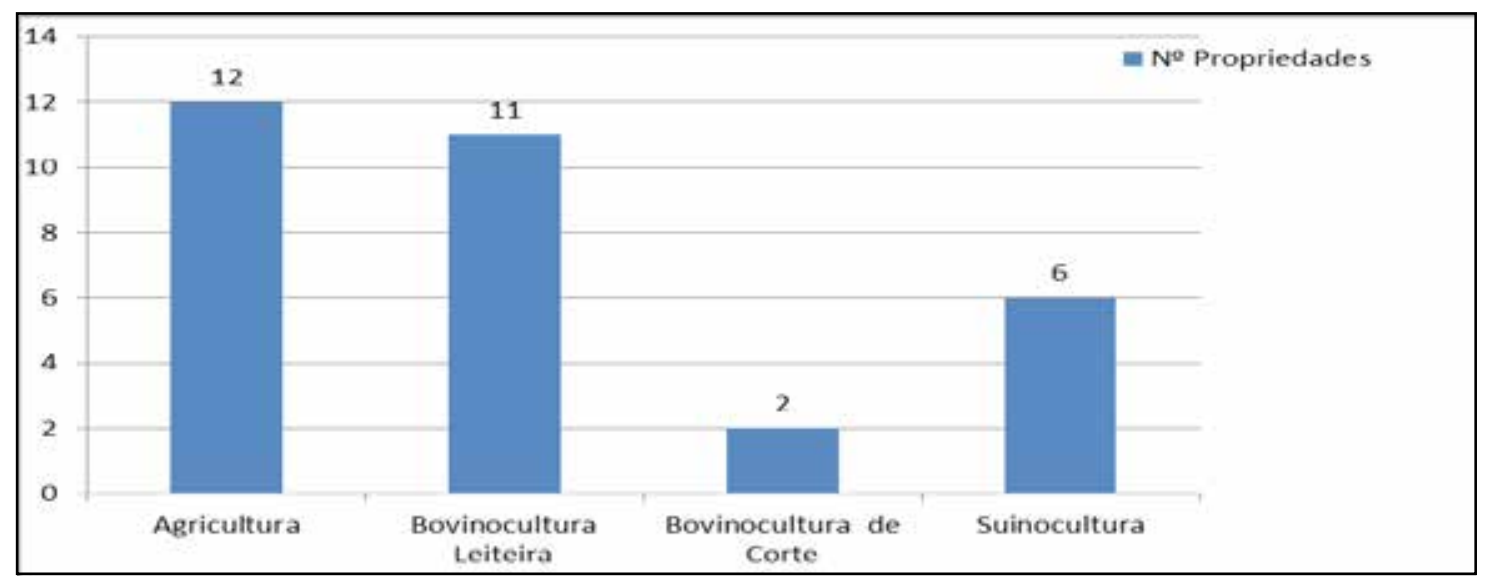

Figura 9 - Principais fontes de renda dos estabelecimentos rurais na área de estudo

não conseguiram se inserir no novo modelo de sistema produtivo.

Sendo assim, estes foram obrigados a migrarem para as cidades e/ou para outros municípios em busca de trabalho para melhorar as condições financeiras das famílias, a fim de, pagar suas dívidas que foram contraídas com bancos na tentativa de se inserirem na modernização da agricultura.

No entanto, as desigualdades produzidas no campo são fruto da diferenciação econômica provocada pela modernização da agricultura. As empresas multinacionais, através do desenvolvimento de novas tecnologias tornam os agricultores dependentes, e estes passam a ser subordinados pela lógica do capital. Aqueles que não conseguem acompanhar este modelo se veem obrigados a deixar o espaço rural e migrar para o meio urbano. Esta afirmação se confirma quando se analisa os dados da população urbana e rural na figura 9 .

A análise dos resultados apresentados no mapa do uso e cobertura do solo (figura 2) demonstram que as áreas agrícolas em 1996, já ocupavam uma área significativa e as áreas de florestas pouco expressivas. Verifica-se que, a concentração das áreas agrícolas está no alto e baixo curso e nas áreas de várzea do rio, evidenciando-se assim, que o cultivo agrícola se desenvolve nas áreas com topografia mais plana, característica que favorece a mecanização da produção e maior produtividade se estendendo em direção ao topo das vertentes.

As áreas destinadas para a agricultura dos últimos anos tiveram e encontram-se em expansão, visto que, nos intervalos analisados (1996 e 2015), as áreas agrícolas produtoras de grãos (agricultura temporária) se expandiram.

O forte crescimento ocorreu principalmente, nos anos de 1995 a 2005, sendo que um dos principais fatores dessa mudança foi o avanço das áreas agrícolas sobre as áreas de florestas.

Este avanço também pode ser observado nos dados dos Censos Agropecuários (IBGE): 1995/96 e 2006, onde a agricultura temporária teve um aumento significativo 
de área no município de Sananduva/RS.

De acordo com o Censo Agropecuário (1996/2012), avaliando o calendário agrícola nesse período, com o cultivo principalmente de soja e milho, se destacam. Destaca-se assim, a expansão da agricultura sobre as áreas de floresta.

\section{Conclusões}

O presente trabalho objetivou analisar a variação da extensão da cobertura vegetal natural e de áreas agrícolas na vertente oeste do alto e médio curso da bacia hidrográfica do arroio Guabiroba no município de Sananduva- RS, entre os anos de 1996 e 2015.

Portanto, o objetivo foi alcançado, e a partir do estudo e análise da paisagem local foi possível identificar os elementos que contribuíram no uso e ocupação do solo, bem como na aceleração do processo de transformação da paisagem uso e cobertura do solo com as transformações da paisagem.

Entre os fatores que condicionaram a transformação da paisagem foi a introdução do setor agropecuários, acelerado pela modernização da agricultura.

A partir da pesquisa a campo encontrou-se áreas de florestas exóticas entre áreas de floresta natural. As florestas naturais encobrem áreas de preservação às nascentes, fornecimento de lenha para o consumo do estabelecimento rural. Portanto, boa parte das famílias que pertencem à agricultura familiar também possui áreas cobertas por vegetação exótica, destacando áreas de eucalipto.

$\mathrm{Na}$ área de estudo destaca-se o cultivo de culturas anuais. As áreas destinadas ao cultivo agrícola sofreram alterações. Pois, a intensificação da mecanização marcou o inicio da modificação da paisagem, do relevo e a expansão das áreas de lavouras agrícolas.

A introdução da vegetação exótica ocorreu como uma forma de utilização do solo. Assim, os produtores fazem o plantio do eucalipto em áreas em que não é mais possível fazer o manejo agrícola. As plantações de eucalipto e pinus surgiram como uma forma de garantir o uso do solo e para fins comerciais.

Neste sentido, na vertente oeste do arroio Guabiroba é composta por elementos naturais (flora, solo, hidrografia) que se contrasta com áreas agrícolas. Desta forma, a paisagem passa a ser uma herança que é deixada de geração para geração.

Portanto, este estudo evidenciou que o uso do solo oriundo das atividades agrícolas tem modificado a paisagem e vem trazendo impacto negativo na conservação das áreas de florestas. Cabe, porém, uma investigação mais precisa quanto às áreas de conflito do uso do solo para propor medidas mitigadoras objetivando a conservação das áreas de florestas no município e uma possível reposição das áreas em conflito.

\section{Agradecimentos}

Aos revisores, colaboradores e agências de fomento.

\section{Referências}

DANTAS, Mayra F: Impactos da modernização da agricultura na estrutura agrária sul mineira na microrregião de Alfenas. MG - 2011. DIÁLOGO FLORESTAL. Disponível em: <http://www.dialogoflorestal.org.br/>. Acessado em 29-10-2014.

IINTITUTO BRASILEIRO DE GEOGRAFIA E ESTATÍSTICA- IBGE. Censo demográfico. Disponível em: http://www.ibge.gov.br/home/estatistica/populacao/ censo2000/. Acessado em 20/03/2015.

INSTITUTO BRASILEIRO DE GEOGRAFIA E ESTATÍSTICA- IBGE. Censo agropecuário. Disponível em: <http://www.ibge.gov.br/home/estatistica/economia/ agropecuaria/censoagro/>. Acessado em 17/11/2014.

INSTITUTO BRASILEIRO DE GEOGRAFIA E ESTATÍSTICA- IBGE. Sistema IBGE de recuperação automática- SIDRA. Disponível em: http://www.sidra. ibge.gov.br/. Acessado em 17-11-2014.

SANTOS, Milton. A Natureza do espaço: Técnica e tempo, razão e emoção. Editora USP, São Paulo, 2002.

CAMARA G, SOUZA RCM, FREITAS UM, GARRIDO J. SPRING: Integrating remote sensingand GIS by objectoriented data modelling. Computers \& Graphics, 20: (3) 395-403, May-Jun 1996. Acessado em 28-05/2015.

UNITED STATES GEOLOGICAL SURVEY(USGS). Mapas, imagens e publicações. Disponível em: http:// www.usgs.gov/pubprod/ > . Acessado em 21/03/2015. 